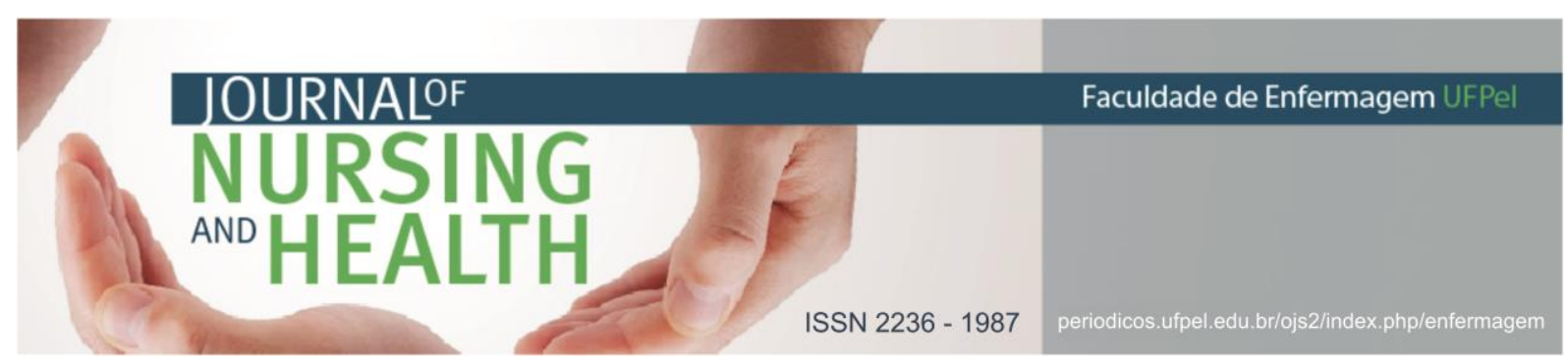

EDITORIAL

\title{
Métodos qualitativos para pesquisa em saúde
}

\author{
Qualitative methods for research on health
}

\section{Métodos cualitativos para la investigación en salud}

Cardano, Mario ${ }^{1}$

Os métodos qualitativos, como observaram Catherine Pope e Nicholas Mays ${ }^{1}$, têm muito a oferecer à pesquisa em saúde. É difícil imaginar acessar a experiência subjetiva de pacientes sem recorrer a entrevistas discursivas, com as quais eles podem moldar suas narrações de doença. Da mesma forma, parece decididamente difícil compreender a complexidade organizacional das práticas de cuidados sem recorrer a formas de observação aproximada que se estende ao longo do tempo. Bem, embora nas últimas décadas, a pesquisa qualitativa em cuidados de saúde se tornou generalizada ${ }^{2}$, ainda há reservas sobre sua capacidade de oferecer um contributo válido para a pesquisa científica. Nesta breve contribuição, proponho em primeiro lugar identificar os traços distintivos da pesquisa qualitativa, para depois discutir seus pontos fortes e fracos. Concluirei com uma breve reflexão sobre as condições que permitem circunscrever os resultados de uma pesquisa qualitativa em um contexto em que há maior familiaridade com ensaios randomizados e pesquisas quantitativas.

A pesquisa qualitativa é tudo menos um monólito, um conjunto compacto de práticas de pesquisa esculpidas na mesma matéria teórica e epistemológica. A pesquisa qualitativa é um conjunto plural de estilos de pesquisa, diferentes por ascendência teórica e práticas de pesquisa. Próxima e imersa em um contexto social, para observá-lo, há aqueles que preferem se envolver em longas conversações, algumas vezes com indivíduos singulares, outras com pequenos grupos de pessoas. Há aqueles que decidem buscar uma resposta às suas perguntas de pesquisa através de uma perturbação intencional do contexto em estudo, conduzida com um claro olhar experimental. Outros reconhecem na perturbação dos fenômenos em estudo a condição a ser evitada e, com a sensibilidade do historiador, eles se concentram em textos e artefatos que podem ser adquiridos sem alterar o contexto social observado. Indubitavelmente diferentes uns dos outros, essas maneiras de fazer pesquisa mostram algumas "semelhanças familiares" importantes ${ }^{3}$. Essas semelhanças, além de identificar os traços relevantes da pesquisa qualitativa, ajudam a reconhecer 0 que a separa da pesquisa quantitativa. Três me parecem ser os traços de pesquisa qualitativa em que este ar familiar é mostrado: a harmonização dos procedimentos de construção de dados com o contexto de seu uso; a observação aproximada, a multivocalidade da escrita.

\footnotetext{
${ }^{1}$ Pesquisador e Professor do Departamento de Cultura, Políticas e Sociedade, Universidade de Turim, Turim, Itália. Email: mario.cardano@unito.it http://orcid.org/0000-0003-0268-3020
} 


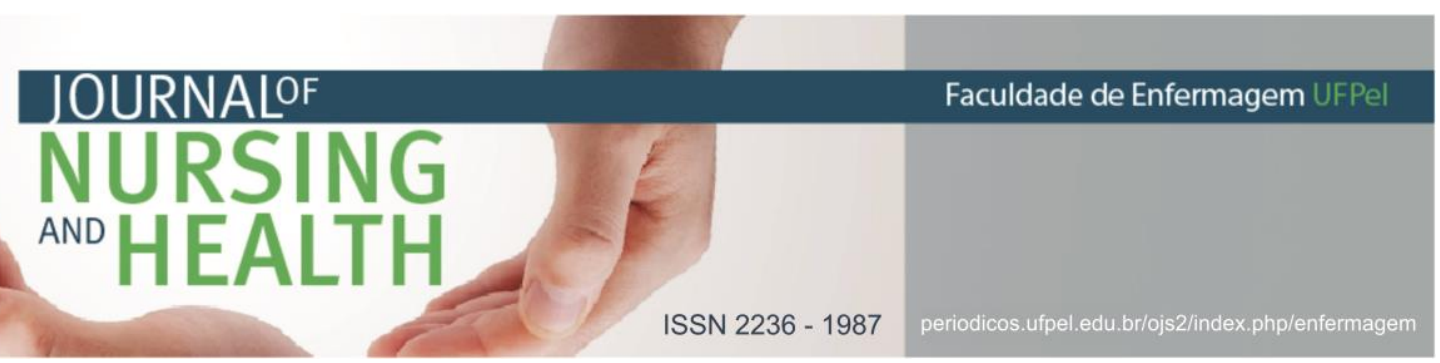

$\mathrm{Na}$ pesquisa qualitativa, os procedimentos de construção de dados assumem configurações diferentes de acordo com o contexto interativo no qual eles tomam forma. Tim Rapley expressa claramente esta vocação da pesquisa qualitativa na indicação de que ele propõe a quem está prestes a realizar um estudo baseado no uso da entrevista discursiva: "Você não precisa fazer a mesma pergunta da mesma maneira em cada interação"5:18. A formulação de uma pergunta, em uma entrevista, sobre a forma como, no decurso de uma pesquisa etnográfica, o pesquisador observará e, até certo ponto, participará de uma prática interativa, variará de tempos em tempos, harmonizando-se com as mudanças circunstanciais do campo. Para colocá-lo em um slogan: na pesquisa qualitativa, não são os participantes que precisam se adaptar ao método proposto, mas é o método que deve se adaptar aos participantes. Na pesquisa quantitativa, por outro lado, os procedimentos de construção de dados são uniformes, regidos por um conjunto de definições operacionais, que, por exemplo, orientam a maneira como as perguntas podem ser feitas em um questionário.

A segunda característica pertinente da pesquisa qualitativa é a sua vocação, conforme James Clifford ${ }^{7}$, a uma observação aproximada, a um estilo de pesquisa que prefere o aprofundamento de detalhes para a reconstrução do quadro geral, os estudos intensivos realizados em um número reduzido de casos, ao invés dos estudos extensivos. Na pesquisa quantitativa, por outro lado, prevalece a tendência de trabalhar em populações ou amostras muito numerosas, também existem estudos baseados em números pequenos, como, por exemplo, em experimentos de laboratório em psicologia ou economia.

O último traço que merece destacar diz respeito ao caráter multivocal, polifônico da escrita com o qual os resultados de uma pesquisa qualitativa são entregues ao leitor. Com poucas exceções, os textos que produzem os resultados de uma pesquisa qualitativa baseiam-se em uma forma de "orquestração" entre a voz do pesquisador e a dos participantes, modulada por uma escala que se apoia no compromisso de dar voz aos participantes ${ }^{8}$, um exercício mais modesto de "ventriloquismo"6:122, em que uma voz, a dos participantes, é, por assim dizer, subserviente aquela do autor. Na pesquisa quantitativa - eu diria sem exceção - os textos que apresentam os resultados de uma pesquisa são monovocais, cruzados pela única voz do autor.

Os pontos fortes da pesquisa qualitativa derivam dos traços distintivos mencionados acima. A observação aproximada e a harmonização dos procedimentos de construção dos dados permitem compreender com precisão particular a "definição da situação" que direciona as ações dos indivíduos e ajuda a definir seu significado. Além disso, é peculiar a capacidade de pesquisa qualitativa para descompactar, por assim dizer, os processos sociais, abrir a caixa preta proverbial que liga os eventos que ocorrem nos contextos em estudo. A abertura dos dispositivos teóricos e metodológicos deste estilo de pesquisa é, além disso, o que permite a formação de novos conceitos, fundados, não em especulações teóricas, mas em materiais empíricos, conforme Mary Morgan ${ }^{9}$, baseados na evidência. Os traços que 


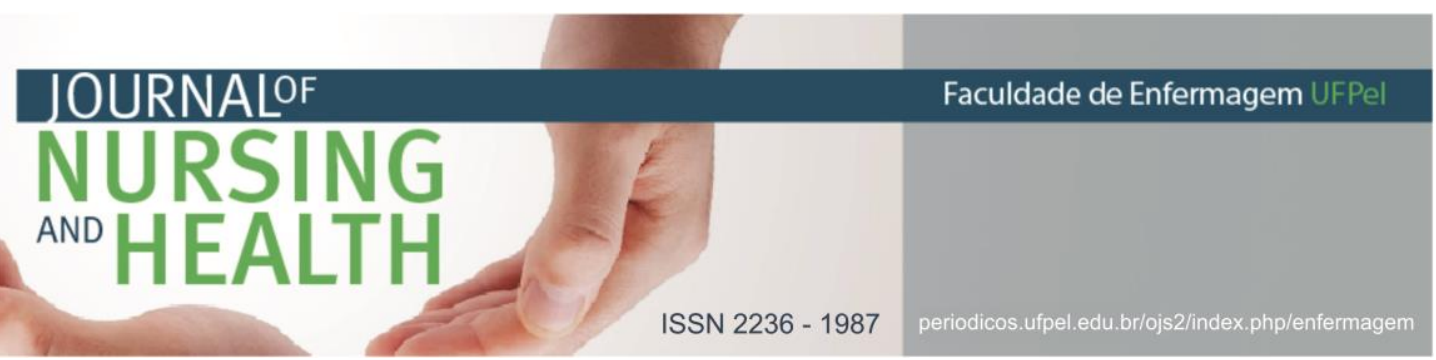

determinam as virtudes da pesquisa qualitativa também são responsáveis pelas fraquezas que the são imputadas: a subjetividade do conhecimento adquirido, a não replicabilidade dos resultados, um modo espirituoso de falar sobre a ausência de rigor.

No entanto, é a opinião do escritor, que esta acusação é formulada através de uma concepção específica de rigor que é precisamente a da pesquisa biomédica e, geralmente é aquela, da pesquisa quantitativa. É um rigor que se baseia na padronização dos procedimentos de coleta e análise de dados e no exame de amostras de grandes ou grandíssimas dimensões. Essas condições permitem prosseguir com a construção do conhecimento usando a "lógica da inferência" ${ }^{10}$, mas o que, de fato, exclui a pesquisa qualitativa das fileiras das práticas científicas. 0 fato - incontestável - de que a pesquisa qualitativa não pode ser submetida à lógica da inferência não implica que essa maneira de fazer pesquisa não permita defender o rigor de suas conclusões. Nesta linha de pensamento, existem numerosas contribuições metodológicas que insistem na necessidade de usar procedimentos para defender a solidez dos resultados de uma pesquisa qualitativa e critérios diferentes dos propostos para pesquisas quantitativas. Os meus trabalhos mais recentes estão se movendo nessa direção, especialmente com a proposta de basear a plausibilidade dos resultados de uma pesquisa qualitativa, usando, ao invés da teoria da probabilidade, própria da abordagem da pesquisa quantitativa, a teoria da argumentação ${ }^{4}$.

Esta linha de raciocínio - na minha opinião - é a única viável, dado as profundas diferenças que separam as versões quantitativas e qualitativas no "jogo da ciência", abertas a um problema ao qual a parte final deste texto é dedicada. A questão - em poucas palavras - é a de comunicação e reconhecimento mútuo entre diferentes "comunidades de práticas", entre aqueles que praticam pesquisa em saúde de acordo com os cânones do ensaio randomizado, usando métodos quantitativos, daqueles que, em sentido mais amplo, decidem se inspirar em outra Musa, a pesquisa qualitativa. Para garantir que diferentes critérios e procedimentos de avaliação (como a teoria da probabilidade e a teoria da argumentação) possam produzir, não a separação rancorosa entre as formas alternativas de fazer ciência, mas sua integração, se faz necessário um profundo repensar sobre a noção de método, entendido não como uma coleção de regras que atuam como ordens, mas como um conjunto de princípios que recebem uma interpretação diferente de acordo com o contexto em que são aplicados. Estes são princípios que, conforme Gary Brent Madison ${ }^{11}$, são mais parecidos com as leis do direito do que com as da física; princípios para os quais não se dão apenas uma interpretação correta, mas mais do que uma, de acordo com o contexto empregado e cuja aplicação, diferente da sentença de um tribunal, deve ser defendida com argumentos adequados. $\mathrm{Na}$ sequência da reflexão proposta nestas páginas, tudo isso se traduz no reconhecimento de que o princípio geral do rigor pode ser considerado respeitado por procedimentos que assumem diferentes formas em pesquisa quantitativa e pesquisa qualitativa. Por exemplo, o princípio inalienável que exige que a comunidade científica explique a forma como os resultados de seu estudo foram 
obtidos (responsabilidade ética) será satisfeito: na pesquisa quantitativa, com uma ilustração das definições operacionais adotadas e os modelos estatísticos adotados; na pesquisa qualitativa, com a elaboração de um relatório reflexivo, que - quando a pesquisa é concluída - descreve detalhadamente como o pesquisador experimentou seu próprio objeto ${ }^{4,12}$. Neste sentido, com críticas ainda não marcadas por um ecumenismo genérico, de que qualquer coisa serve, é possível expressar plenamente o potencial da pesquisa qualitativa na área da saúde.

Descritor: Pesquisa Qualiativa.

Notas do autor:

${ }^{i}$ No texto, refiro-me às técnicas de pesquisa qualitativa mais comuns: observação participante ou naturalista, shadowing, entrevista discursiva e grupo focal, experiência de campo e jogos, observação de documentos naturais (de textos, imagens de vídeo, objetos de cultura material) e análise de conversações. Para um mapa de técnicas de pesquisa qualitativa ${ }^{4}$.

ii Barbara Czarniawska, escreve em Narrative in Social Science Research que: "Se existe uma regra geral sobre pesquisa de campo é que todas as técnicas devem ser sensíveis ao contexto"6:44.

\section{REFERÊNCIAS}

1. Pope C, Mays N. Qualitative Research in Health Care. $2^{\text {nd }}$ ed. London: BMJ Books; 2000.

2. Green J, Torogood N. Qualitative Methods for Heath Research $3^{\text {rd }}$ ed. London: Sage; 2014.

3. Wittgeinstein L. Investigações filosóficas. Petropolis: Vozes; 2014.

4. Cardano M. Manual de pesquisa qualitativa: a contribuição da teoria da argumentação. Petrópolis: Vozes; 2017.

5. Rapley T. Interviews, in: Seale C, Gobo G, Gubrium JF, Silverman D (editors). Qualitative Research Practice. London: Sage; 2004. p.15-33.

6. Czarniawska B. Narrative in Social Science Research. London: Sage; 2004.

7. Clifford J. Routes. Travel and Translation in the Late Twentieth Century, Cambridge (Mass.). London: Harvard University Press; 1997

8. Tedlock D. Questions concerning Dialogical Anthropology. Journal of Anthropological Research. 1987;43(4):325-37.

9. Morgan M. Case Studies in: Cartwright N, Montuschi E (editors). Philosophy of Social Sciences. A New Introduction. Oxford: Oxford University Press; 2014.p. 288307.

10. Goldthorpe J. On Sociology. Narratives, and the Integration of Research and Theory. Oxford: Oxford University Press; 2000.

11. Madison GB.The hermeneutics of postmodernity. Bloomington: Indiana University Press; 1988. 


\section{JOURNALOF

12. Altheide DL, Johnson JM. Criteria for Assessing Interpretive Validity in Qualitative Research in: Denzin NK, Lincoln YS (editors). Handbook of Qualitative Research. London: Sage; 1994. p.485-499.

Data de submissão: 20/11/2017

Data de aceite: 08/12/2017

Data de publicação: 26/12/2017 